\title{
Kondisi Saluran Drainase Candi Borobudur dan Konsep Penanganannya
}

\section{Condition of Drainage Channel in Borobudur Temple and its Conservation}

\author{
Leliek Agung Haldoko, Wahyudi, Basuki Rachmat \\ Al. Widyo Purwoko \\ Balai Konservasi Borobudur \\ Sur-el : leliek_agung@yahoo.co.id
}

\begin{abstract}
ABSTRAK
Candi Borobudur merupakan salah satu warisan budaya Indonesia yang telah diakui sebagai salah satu warisan budaya dunia. Pada pemugaran kedua (1973-1983) dibuat sistem drainase untuk menyalurkan air melalui pipa-pipa yang berada dalam tubuh candi hingga ke bak kontrol dan berakhir pada sumur peresapan. Kondisi sistem drainase Candi Borobudur mengalami penurunan fungsi seiring berjalannya waktu.

Hasil kajian menunjukkan pada saluran filter layer terdapat banyak endapan tanah/pasir yang menghambat aliran air keluar dari dalam bukit Candi Borobudur. Endapan tanah/pasir pada saluran filter layer bukan berasal dari tanah bukit tetapi dari endapan pada saluran drainase bawah lantai yang terbawa masuk. Selain itu sebagian filter layer dalam kondisi rusak dan beberapa yang lain belum dapat diidentifikasi kondisinya. Meskipun filter layer dalam kondisi rusak tetapi fungsinya sebagai lapisan penyaring masih bekerja baik.

Endapan tanah/pasir pada saluran drainase bawah lantai akan mengganggu kelancaran aliran air karena posisi dasar saluran drainase menjadi lebih tinggi dan membuat dasar saluran menjadi rata/kemiringannya berkurang. Pada saluran drainase halaman-lereng, tidak adanya aliran air yang terukur pada outlet saluran drainase Selatan 2 (S2) dan Timur (T); mengindikasikan adanya permasalahan pada kedua saluran drainase tersebut yaitu terjadinya kebocoran saluran.

Untuk mengoptimalkan monitoring geohidrologi dilakukan perubahan metode monitoring filter layer dari yang sebelumnya dengan mengukur debit dan kekeruhan air yang keluar dari bukit dan melewati filter layer, menjadi monitoring menggunakan videoscope untuk mengamati gambaran visual filter layer. Selain itu menghentikan monitoring muka air tanah melalui pipa inklinometer karena sebagian besar pipa inklinometer memiliki ujung bawah pipa tertutup sehingga data yang didapatkan tidak valid. Pada akhirnya dari data yang didapatkan, kecil kemungkinan air tanah bukit Candi Borobudur akan meluap dan menekan struktur Candi Borobudur.
\end{abstract}

Kata Kunci: Candi Borobudur, filter layer, saluran drainase, air, air tanah, bukit

\section{ABSTRACT}

Borobudur Temple is one of Indonesia's cultural heritage site that has been enlisted as World Heritage. In its second restoration (1973-1983), new drainage system was installed 
to flow water using concrete pipes inside the temple structure to control tank, to be directed to infiltration well. Over time, the efficiency of this system is decreasing.

The study shows that filter layer channels contain much soil/sand sediments that clog the water running outside from the temple structure. The sediments come not from hill soil, but was carried to the channel from under the temple floor. Some filter layers are confirmed to be damaged, while others are still unidentified. However, the damaged filter layers still function well.

The soil/sand sediments on drainage channel under the floor would disturb the flow of the water because the elevation for water to be able to run off would be compromised. In the courtyard-slope drainage channel, no water volume can be calculated in channel South 2 (S2) and East (T); indicating that there is a leakage in the channel.

To optimize the geohydrology monitoring in Borobudur Temple, a change in monitoring methodology is needed to evaluate the effectiveness of filter layers from assessing the water discharge and turbidity of water coming out from the hill to controlling the condition of filter layer channels using videoscope through visual imagery. Measurement of ground water level using inclinometer pipe is not valid because most of the pipes are closed off at their far end. From the data gathered, it is less possible for the ground water in the hill of Borobudur Temple to overflow and push the structure of Borobudur Temple.

Keywords: Borobudur Temple, filter layer, drainage channel, water, ground water, hill

\section{PENDAHULUAN}

Candi Borobudur merupakan salah satu warisan budaya Indonesia yang juga telah diakui sebagai salah satu warisan budaya dunia. Candi Borobudur dibangun sekitar tahun 800-an Masehi oleh para penganut agama Buddha Mahayana pada masa pemerintahan Raja Samaratungga yang berasal dari wangsa atau dinasti Syailendra dan merupakan tempat pemujaan bagi pemeluk agama Budha. Lokasi Candi Borobudur terletak di Desa Borobudur, Kecamatan Borobudur, Kabupaten Magelang. Secara astronomis Candi Borobudur terletak pada $7,7^{\circ}$ lintang selatan dan $110^{\circ}$ bujur timur.

Pada tahun 1907-1911 T. Van Erp memulai restorasi terhadap Candi Borobudur. T. Van Erp memulai pekerjaan dengan melakukan restorasi terhadap pagarpagar langkan, dinding lorong pertama, saluran-saluran air di lereng bukit, tangga-tangga bagian bawah, gapura-gapura dan relung-relung beserta stupa-stupa kecilnya. Kemudian pada tahun 1973-1983, pemerintah Indonesia bekerja sama dengan UNESCO melakukan restorasi besar-besaran terhadap Candi Borobudur, dengan harapan dapat bertahan selama 1.000 tahun (Soekmono, 1972).

Pasca pemugaran yang pertama, air hujan masih mengalir melalui jaladwara yaitu semacam talang saluran air yang berfungsi menyalurkan air hujan dari lantai lorong ke lantai lorong di bawahnya. Sedangkan setelah pemugaran yang kedua telah dibuat sistem saluran air yang disalurkan melalui pipa-pipa yang berada dalam tubuh candi lorong I-IV hingga ke bak kontrol dan berakhir pada sumur peresapan yang berada di bawah lereng bukit. Air 
hujan diatasi dengan membuat lapisan kedap air untuk mencegah rembesan air ke permukaan batu luar terutama ke bagian relief. Sedangkan pada bagian-bagian tertentu yaitu di bagian bawah pagar langkan dan bagian bawah dinding lorong I-V dipasang lapisan timah hitam: selain untuk meratakan beban juga untuk mencegah kapilarisasi pada batu candi. Untuk menyaring air tanah yang keluar dari dalam tanah bukit dipasang lapisan penyaring (filter layer) agar tidak ada tanah bukit yang terbawa oleh air tanah yang keluar.

Kondisi sistem drainase Candi Borobudur yang telah dibuat pada pemugaran kedua (1973-1983) tentunya akan mengalami penurunan fungsi seiring berjalannya waktu. Karena itu perlu dipastikan apakah sistem drainase Candi Borobudur yang dibuat pada pemugaran kedua dan sesudahnya masih berfungsi dengan baik.

\section{KONDISI EKSISTING DAN PERMASALAHAN PADA SISTEM DRAINASE CANDI BOROBUDUR}

\section{Lapisan Penyaring (filter layer)}

Untuk menyaring air tanah yang keluar dari dalam tanah bukit Candi Borobudur dipasang lapisan penyaring/filter layer agar tidak ada tanah bukit yang terbawa oleh aliran air yang keluar. Selain itu terdapat saluran filter layer yaitu saluran sepanjang sekitar 3 meter untuk mengalirkan air yang keluar dari tanah bukit melalui filter layer menuju ke saluran drainase bawah lantai. Lokasi filter layer berada di belakang dinding lorong I-IV Candi

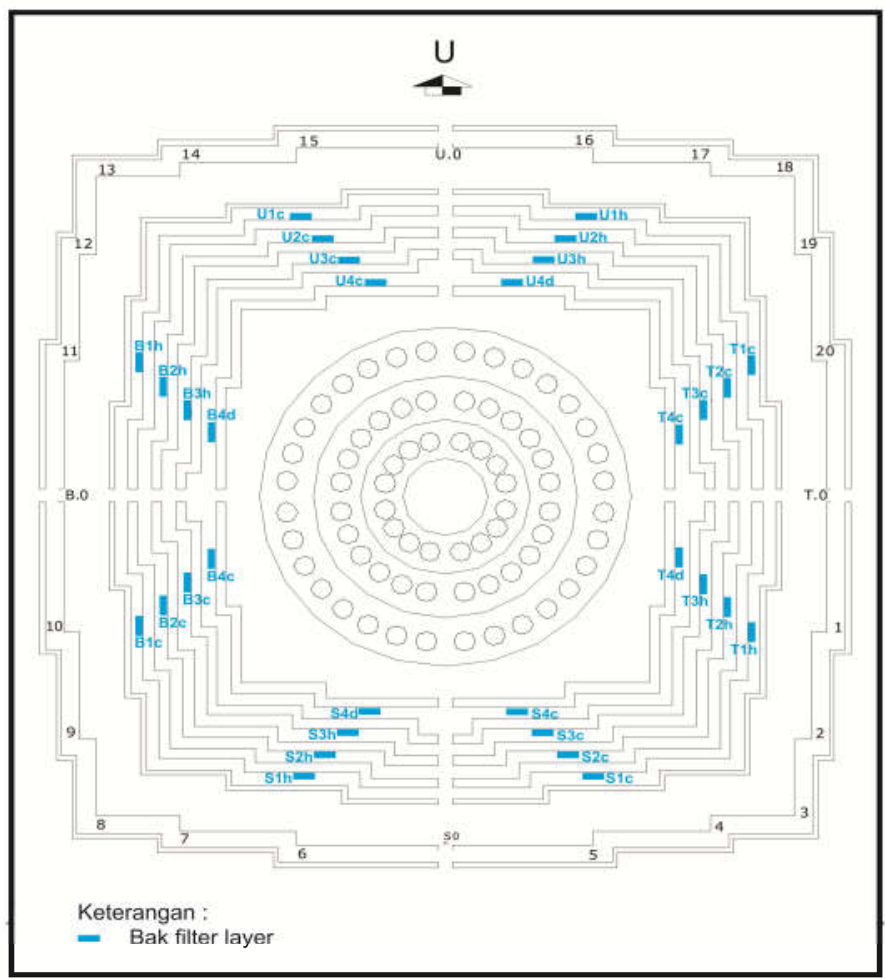

Gambar 1. Lokasi bak penampung air di ujung saluran filter layer 


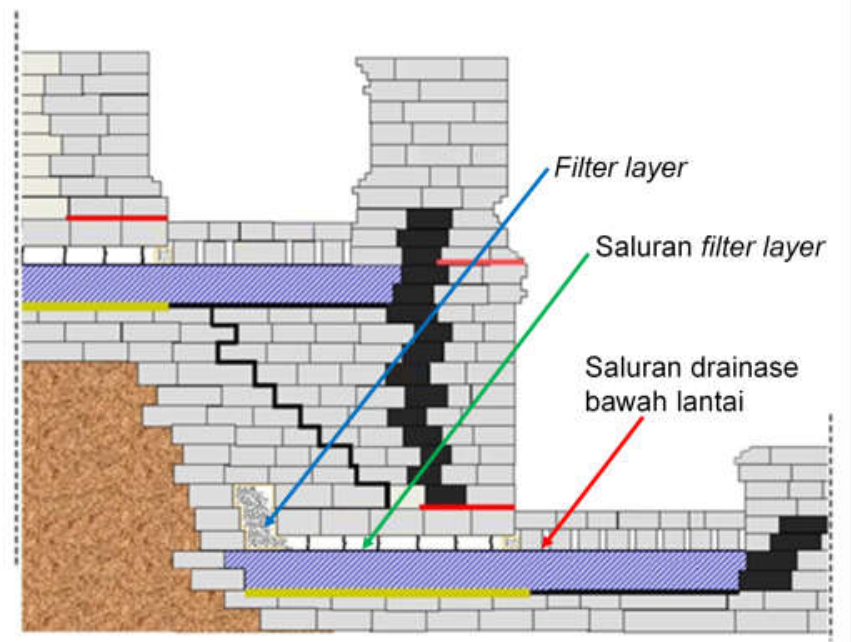

Gambar 2. Posisi filter layer, saluran filter layer dan saluran drainase bawah lantai

Borobudur di semua sisi. Pada masing-masing lorong setiap jarak 5 meter terdapat filter layer, tetapi hanya 8 filter layer yang pada ujung saluran filter layer-nya dibuat bak penampung air sehingga total terdapat 32 bak penampung.

Material filter layer terdiri dari kerakal, kerikil, dan pasir yang dibungkus dengan geotekstil dan dipasang menerus mengelilingi tubuh candi. Karena di sekitarnya sudah dipasang lapisan kedap air maka, air dari dalam bukit akan keluar melewati filter layer, sehingga tidak ada tanah bukit yang keluar karena telah tersaring oleh lapisan ini.

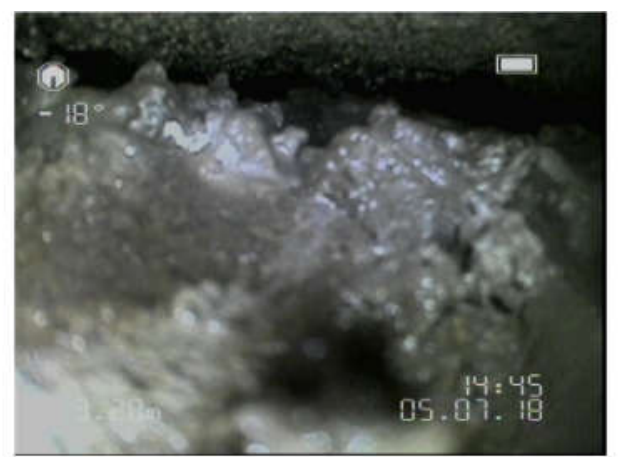

Gambar 3. Kondisi saluran filter layer yang tertutup endapan lumpur
Pengamatan kondisi filter layer pada awalnya dilakukan dengan mengukur debit air dan kekeruhan air yang keluar melewati filter layer. Akan tetapi metode ini ternyata tidak efektif dan hasil yang didapatkan menjadi kurang valid. Hal ini dikarenakan debit dan kekeruhan air sangat dipengaruhi oleh banyaknya endapan material pada saluran filter layer sementara endapan material pada tiap-tiap saluran filter layer tidak sama. Karena itu pengamatan kondisi filter layer dilakukan dengan alat videoscope yaitu kamera kabel yang dapat dimasukkan ke celah sempit (saluran filter layer) untuk mengamati

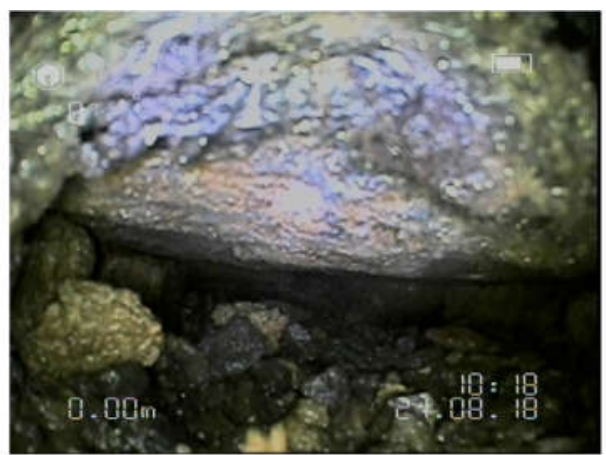

Gambar 4. Kondisi saluran filter layer tertutup material kerikil-kerakal yang diindikasikan berasal dari filter layer yang telah rusak 
gambaran visual filter layer dan kondisi saluran filter layer. Hal ini dikarenakan saluran filter layer sangat sempit yaitu hanya memiliki tinggi 5$10 \mathrm{~cm}$.

Dari hasil pengamatan terlihat bahwa sebagian filter layer diindikasikan dalam kondisi rusak dan beberapa yang lain belum dapat diidentifikasi kondisinya karena beberapa hal seperti :

a. Dalam saluran filter layer terdapat endapan lumpur yang mengotori ujung kamera sehingga gambar yang didapatkan menjadi tidak jelas/ buram/ sama sekali tidak terlihat.

b. Dalam saluran filter layer terdapat banyak air yang merendam ujung kamera sehingga gambar yang didapatkan menjadi tidak jelas/ buram/ sama sekali tidak terlihat.

c. Kamera tidak dapat menjangkau sampai ke ujung dalam saluran karena penyempitan saluran di bagian dalam.

Meskipun filter layer dalam kondisi rusak (geotekstil sobek/ material pengisinya keluar) tetapi fungsinya sebagai lapisan penyaring masih bekerja baik. Hal ini ditunjukkan dengan kondisi material pengisi filter layer (kerakal, kerikil, pasir) yang masih penuh menutup ujung dalam saluran filter layer. Selain itu juga dilakukan pengujian untuk membandingkan ukuran butir endapan material pada saluran filter layer dan endapan material pada saluran drainase bawah lantai. Hasilnya disajikan pada Tabel 1.

Dari hasil pengujian ukuran butir material dapat diidentifikasi bahwa material pada saluran filter layer sama dengan material pada saluran drainase bawah lantai karena memiliki distribusi ukuran butir yang hampir sama. Jadi endapan material pada saluran filter layer bukan berasal dari tanah bukit tetapi dari saluran drainase bawah lantai yang terbawa masuk. Ini berarti meskipun filter layer dalam kondisi rusak tetapi masih dapat menyaring tanah bukit Candi Borobudur.

Meskipun demikian endapan material pada saluran drainase perlu dibersihkan karena akan menghambat keluarnya air dari dalam bukit yang melewati filter layer untuk menuju saluran drainase bawah lantai. Hal ini dikarenakan endapan material akan menutup saluran.

Selain itu kondisi lain yang dijumpai adalah sangat sedikitnya (hanya di beberapa titik) ditemukan

Tabel 1. Ukuran butir endapan material pada saluran filter layer dan dari saluran drainase bawah lantai

\begin{tabular}{|c|c|c|c|}
\hline \multicolumn{2}{|c|}{ Ukuran butir } & \multirow{2}{*}{$\begin{array}{c}\begin{array}{c}\text { Saluran filter } \\
\text { layer } \\
\text { (\%) }\end{array} \\
3\end{array}$} & \multirow{2}{*}{$\begin{array}{c}\begin{array}{l}\text { Saluran drainase } \\
\text { bawah lantai (\%) }\end{array} \\
3\end{array}$} \\
\hline$>2 \mathrm{~mm}$ & gravel & & \\
\hline $1-2 \mathrm{~mm}$ & Pasir sangat kasar & 5 & 3 \\
\hline $0,5-1 \mathrm{~mm}$ & Pasir kasar & 10 & 13 \\
\hline $0,25-0,5 \mathrm{~mm}$ & Pasir sedang & 25 & 27 \\
\hline $0,125-0,25 \mathrm{~mm}$ & Pasir halus & 35 & 31 \\
\hline $0,063-0,125 \mathrm{~mm}$ & Pasir sangat halus & 16 & 18 \\
\hline \multirow[t]{2}{*}{$<0,063 \mathrm{~mm}$} & Lanau-lempung & 6 & 5 \\
\hline & & 100 & 100 \\
\hline
\end{tabular}




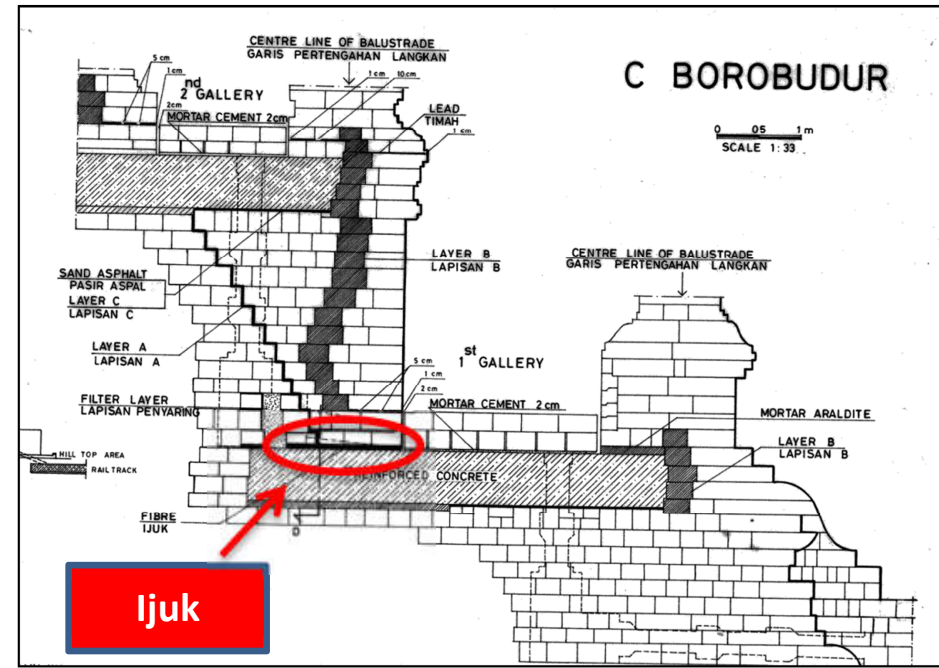

Gambar 5. Posisi lapisan ijuk pada saluran filter layer yang dipasang pada pemugaran tahun 1973-1983

ijuk pada saluran filter layer. Padahal ketika saluran ini dibuat pada masa pemugaran ke-2 (1973-1983) sepanjang saluran filter layer diberi pasangan ijuk yang berfungsi untuk menyaring air sebelum dan setelah melewati filter layer.

Berdasarkan informasi dari beberapa purnatugas Balai Konservasi Borobudur serta kajiankajian yang dilakukan sebelumnya tidak pernah dilakukan pengambilan/pembersihan ijuk pada saluran filter layer. Hal ini menarik karena material ijuk merupakan material yang elastis, keras dan tahan air, dan sulit dicerna oleh organisme perusak serta memilik keistimewaan yaitu dapat bertahan lama hingga ratusan bahkan ribuan tahun lebih (Supriyadi, 2017). Sehingga penyebab yang paling memungkinkan untuk hilangnya ijuk pada setiap saluran filter layer adalah karena ijuk terbawa aliran.

\section{Saluran Drainase Bawah Lantai}

Lantai lorong I-IV dan lantai plateu dibuat dengan memiliki celahcelah antar batu sehingga air hujan akan mudah masuk ke bawah lantai. Penyangga lantai dibuat parit-parit dari batu andesit yang disusun renggang sehingga menjadi saluran
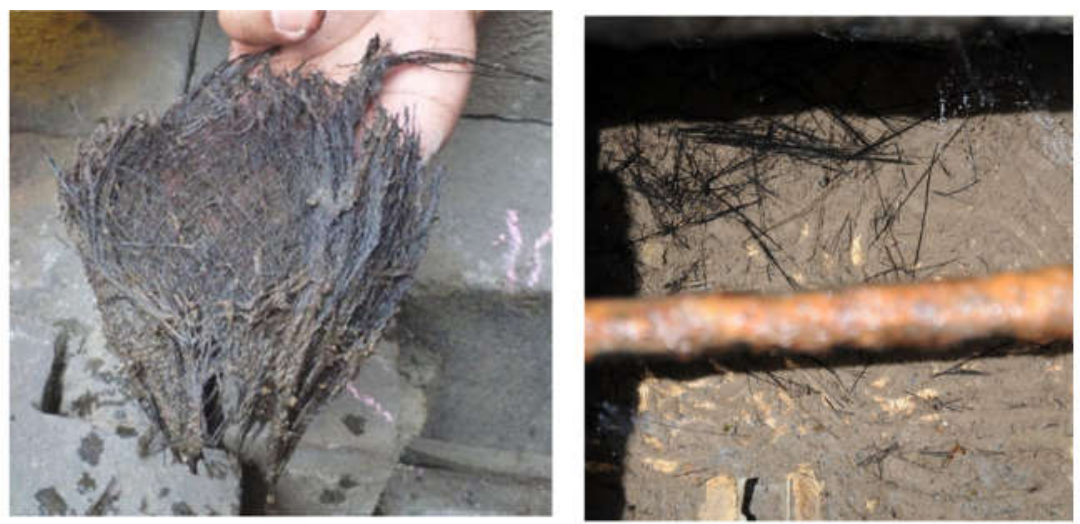

Gambar 6. Iiuk vang ditemukan pada uiung luar saluran filter laver 

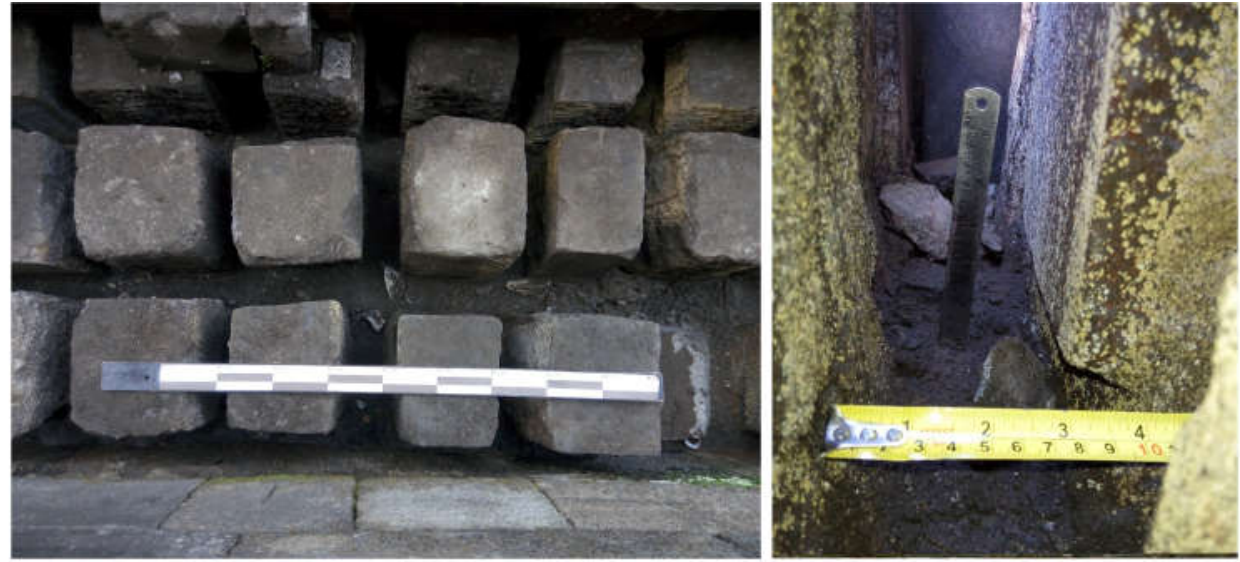

Gambar 7. Kondisi saluran drainase bawah lantai yang terisi endapan tanah/pasir

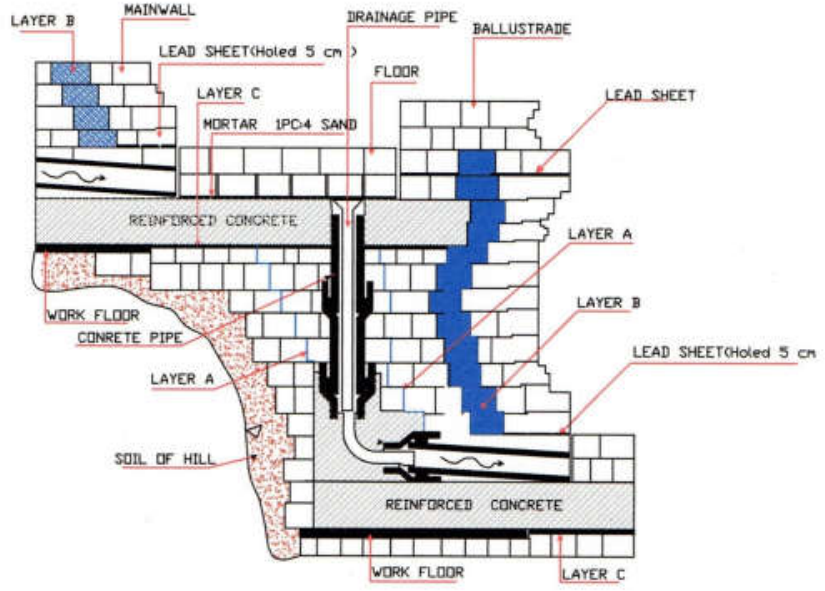

Gambar 8. Posisi saluran drainase bawah lantai

drainase bawah lantai. Saluran air ini dibuat miring dan mengarah ke lubang saluran vertikal (saluran antar lantai) untuk mengalirkan air ke tingkat-tingkat di bawahnya hingga sampai ke sumur peresapan yang berada pada lembah bukit candi.

Kondisi eksisting saluran drainase bawah lantai saat dilakukan pengecekan dalam kondisi dasar saluran terisi endapan material tanah/pasir setebal 2-5 cm dan banyak sampah plastik. Endapan material ini bersumber dari beberapa hal yaitu :

a. Alas kaki pengunjung membawa material tanah ketika naik ke atas candi dan kemudian jatuh di lantai lalu masuk ke saluran drainase bawah lantai

b. Material tanah/pasir terbawa oleh angin kemudian jatuh di lantai lalu masuk ke saluran drainase bawah lantai

c. Material batu candi yang mengalami pelapukan maupun yang terkikis oleh alas kaki pengunjung dan masuk ke saluran drainase bawah lantai

d. Sisa dari abu erupsi Gunung Kelud tahun 2014 yang masuk ke saluran drainase bawah lantai

e. Sampah dari pengunjung yang dibuang di lantai 


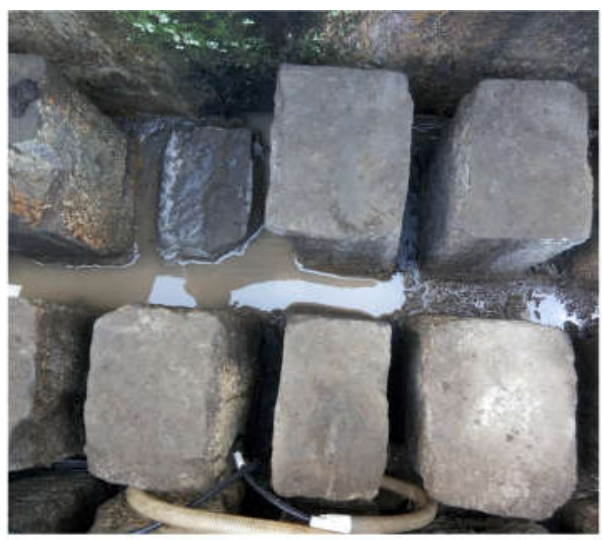

Gambar 9. Kondisi air yang menggenang pada saluran drainase bawah lantai

Keberadaan

endapan tanah/pasir pada saluran drainase bawah lantai tentunya akan mengganggu kelancaran aliran air yang melewati saluran ini. Hal ini karena posisi dasar saluran drainase menjadi lebih tinggi dan membuat dasar saluran menjadi rata (berkurang kemiringannya). Jika terdapat air dalam jumlah yang tidak terlalu banyak, air tersebut tidak dapat mengalir menuju saluran air vertikal dan cenderung menggenang.

Saluran drainase bawah lantai ini sangat erat kaitannya dengan saluran filter layer. Endapan material pada saluran drainase bawah lantai akan berpengaruh terhadap saluran filter layer karena memiliki elevasi yang sama. Ketika terjadi hujan maka air hujan yang masuk ke saluran drainase bawah lantai akan membawa tanah/pasir masuk ke saluran filter layer. Hal inilah yang menyebabkan saluran filter layer tertutup oleh tanah/pasir dan pada akhirnya akan menghambat keluarnya air dari dalam bukit yang melewati saluran filter layer.

\section{RENCANA PENANGANAN PERMASALAHAN SISTEM DRAINASE BOROBUDUR}

\section{Filter layer}

Kondisi saluran filter layer yang tertutup tanah/pasir akan menyebabkan terhambatnya air dari dalam bukit yang melewati saluran filter layer untuk keluar menuju saluran drainase bawah lantai. Jika kondisi ini dibiarkan dan pada akhirnya semua saluran filter layer tertutup oleh tanah/pasir maka air dari dalam bukit Candi Borobudur tidak dapat keluar menuju saluran

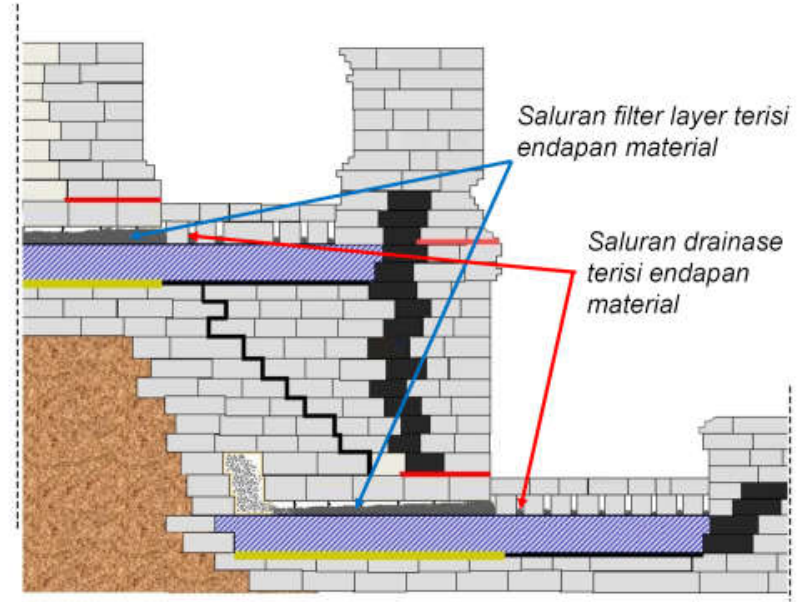

Gambar 10. Saluran filter layer dan saluran drainase bawah lantai terisi oleh endapan material tanah/pasir 
drainase. Hal ini menyebabkan air akan terakumulasi di tubuh bukit candi dan berpotensi menekan struktur candi karena tidak mempunyai jalan keluar. Karena itu sangat penting untuk memastikan semua saluran filter layer tidak tertutup oleh tanah/pasir sehingga dapat mengalirkan air dengan lancar. Untuk itu perlu dilakukan pembersihan saluran filter layer.

Karena kondisi saluran filter laver sangat sempit (tinggi $5-10 \mathrm{~cm}$ ) dengan panjang mencapai 3 meter maka pembersihannya tidak dapat dilakukan dengan alat penggaruk. Pembersihan hanya dapat dilakukan dengan air bertekanan dan mesin penyedot lumpur. Prinsip kerjanya adalah :

a. Air bertekanan disemprotkan ke saluran filter layer dengan alat water pressure.

b. Material tanah/pasir yang menutup saluran filter layer akan terbawa keluar bersama air

c. Material tanah/pasir yang keluar bersama air disedot dengan alat penyedot lumpur

Selama proses pembersihan dilakukan pengamatan kondisi visual

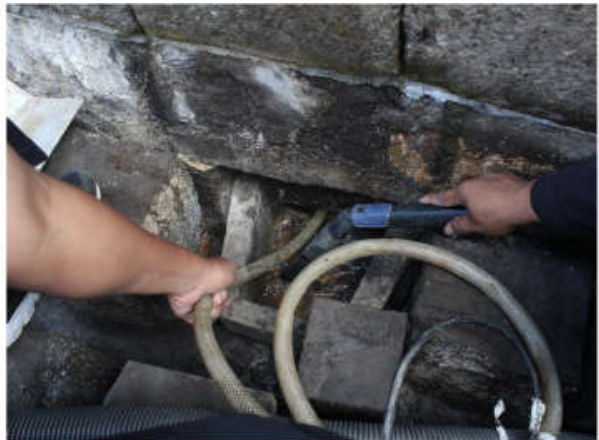

Gambar 11. Penyemprotan dengan air bertekanan dilanjutkan penyedotan air dan lumpur

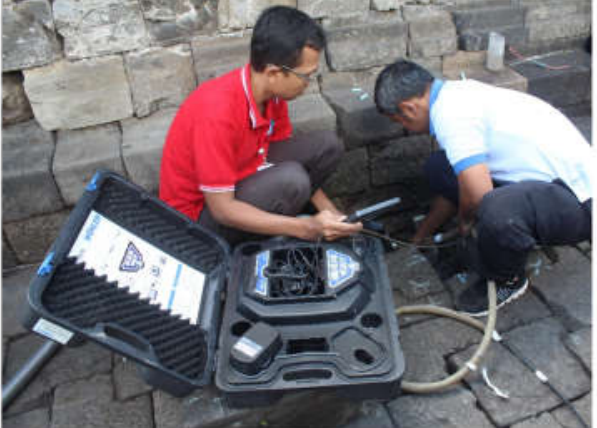

Gambar 12. Pengamatan dengan videoscope selama proses pembersihan

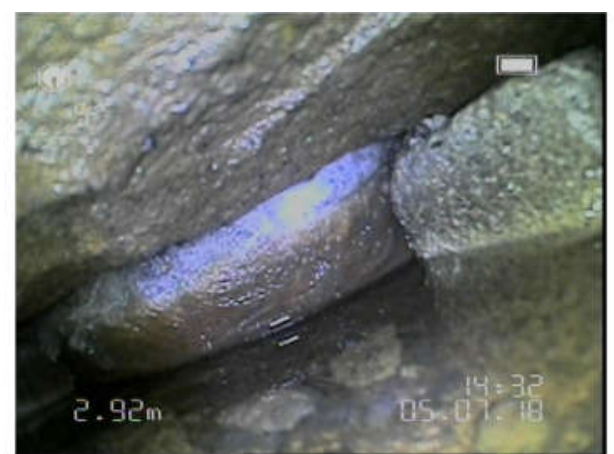

Gambar 13. Filter layer dalam kondisi baik, geotekstil masih utuh

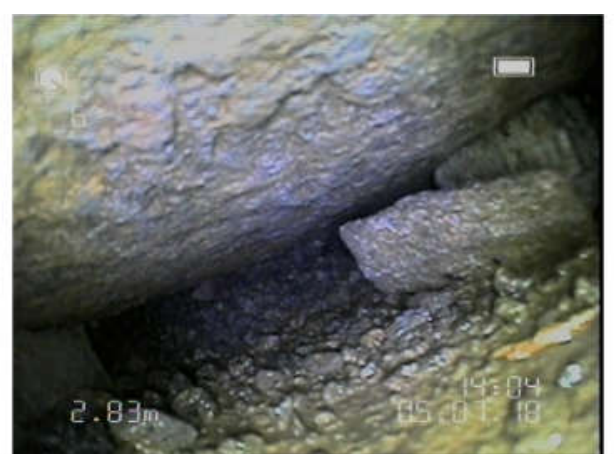

Gambar 14. Filter layer dalam kondisi rusak, geotekstil sudah hancur/sobek

saluran filter layer dengan videoscope. Hal ini untuk memastikan saluran filter laver telah bersih dari endapan tanah/pasir. Jika kondisinya belum bersih maka proses pembersihan terus dilanjutkan sampai saluran filter layer benar-benar bersih. 


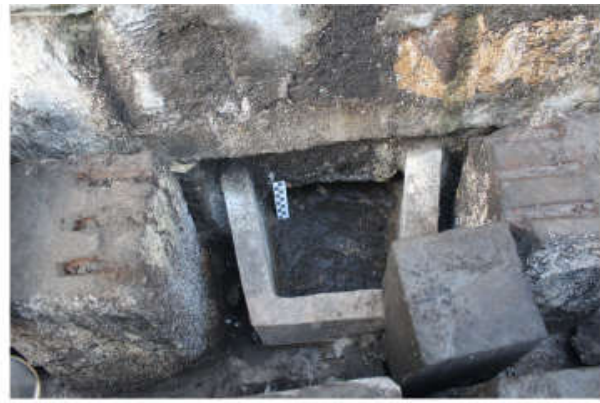

Gambar 15. Bak penampung air pada ujung luar saluran filter layer membuat aliran air tertahan dan tidak dapat mengalir menuju saluran drainase bawah lantai

Setelah saluran filter layer benar-benar bersih selanjutnya dilakukan pengamatan kondisi filter layer secara visual. Hal ini untuk melihat apakah filter layer dalam kondisi baik atau telah mengalami kerusakan.

Setelah dilakukan pembersihan pada saluran filter layer terlihat jelas bagian filter layer yang sebelumnya tertutup oleh endapan material. Secara umum kondisi filter layer dibagi menjadi 2 yaitu filter layer yang lapisan geotekstilnya masih utuh dan filter layer yang lapisan geotekstilnya telah rusak. Meskipun demikian untuk filter layer yang lapisan geotekstilnya telah rusak tetap masih dalam kondisi yang dapat menyaring menyaring tanah bukit Candi Borobudur.

Dari percobaan yang telah dilakukan, waktu yang diperlukan untuk membersihkan 1 saluran filter layer sekitar 60 menit (1 jam). Dengan asumsi bahwa setiap interval 5 meter terdapat saluran filter layer maka jumlah saluran filter layer adalah sebanyak 188 saluran (termasuk 32 saluran dengan bak penampung air) dengan rincian sebagai berikut :

- Lorong I : 68 saluran

- Lorong II : 48 saluran

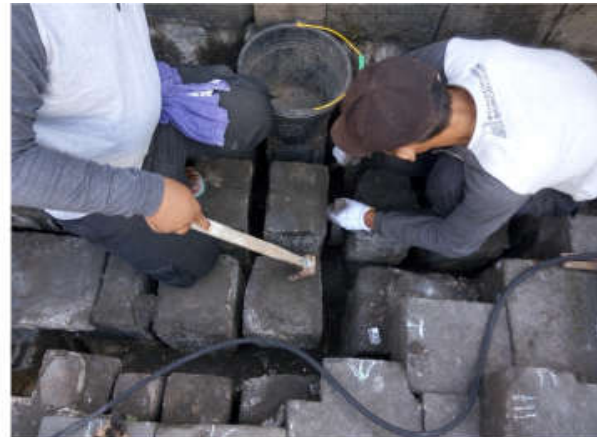

Gambar 16. Proses pembersihan saluran drainase bawah lantai bawah lantai

- Lorong III : 40 saluran

- Lorong IV : 32 saluran

Selain itu keberadaan bak penampung air pada ujung saluran filter layer (32 saluran) membuat air tertahan dan tidak bisa mengalir ke saluran drainase bawah lantai. Untuk itu perlu dilakukan pembongkaran bak penampung air tersebut agar air dapat mengalir lancar menuju saluran drainase bawah lantai.

\section{Saluran Drainase Bawah Lantai}

Kondisi saluran drainase bawah lantai yang terisi oleh endapan tanah/pasir tentunya akan mengganggu kelancaran aliran air yang melewati saluran ini. Selain itu ketika terjadi hujan maka air hujan yang masuk ke saluran drainase bawah lantai akan membawa tanah/pasir masuk ke saluran filter layer. Oleh sebab itu saluran filter layer tertutup oleh tanah/pasir dan pada akhirnya akan menghambat keluarnya air dari dalam bukit yang melewati saluran filter layer. Karena itu penting untuk memastikan saluran drainase bawah lantai dalam kondisi bersih dari endapan tanah/pasir agar air yang melewati saluran ini dapat mengalir dengan lancar serta tidak menghambat keluarnya air yang 


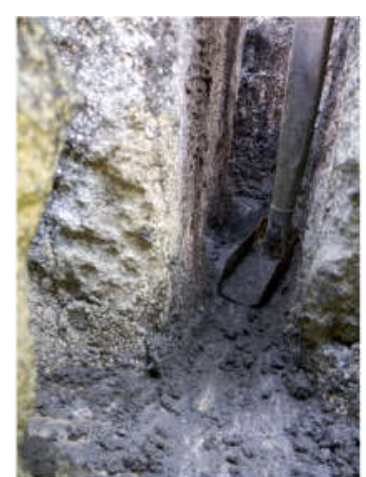

Gambar 17. Penggunaan alat penggaruk khusus pada celah saluran bawah lantai

melewati saluran filter layer. Karena saluran drainase bawah lantai memiliki celah sempit maka untuk pembersihan endapannya menggunakan penggaruk khusus yang dapat masuk ke celah saluran.

Proses pembersihan saluran drainase bawah lantai dilakukan secara simultan dengan pembersihan saluran filter layer. Ini dilakukan agar kedua saluran ini tidak saling mengotori ketika dilakukan pembersihan. Setelah saluran filter laver dan saluran drainase bersih selanjutnya yang dilakukan adalah
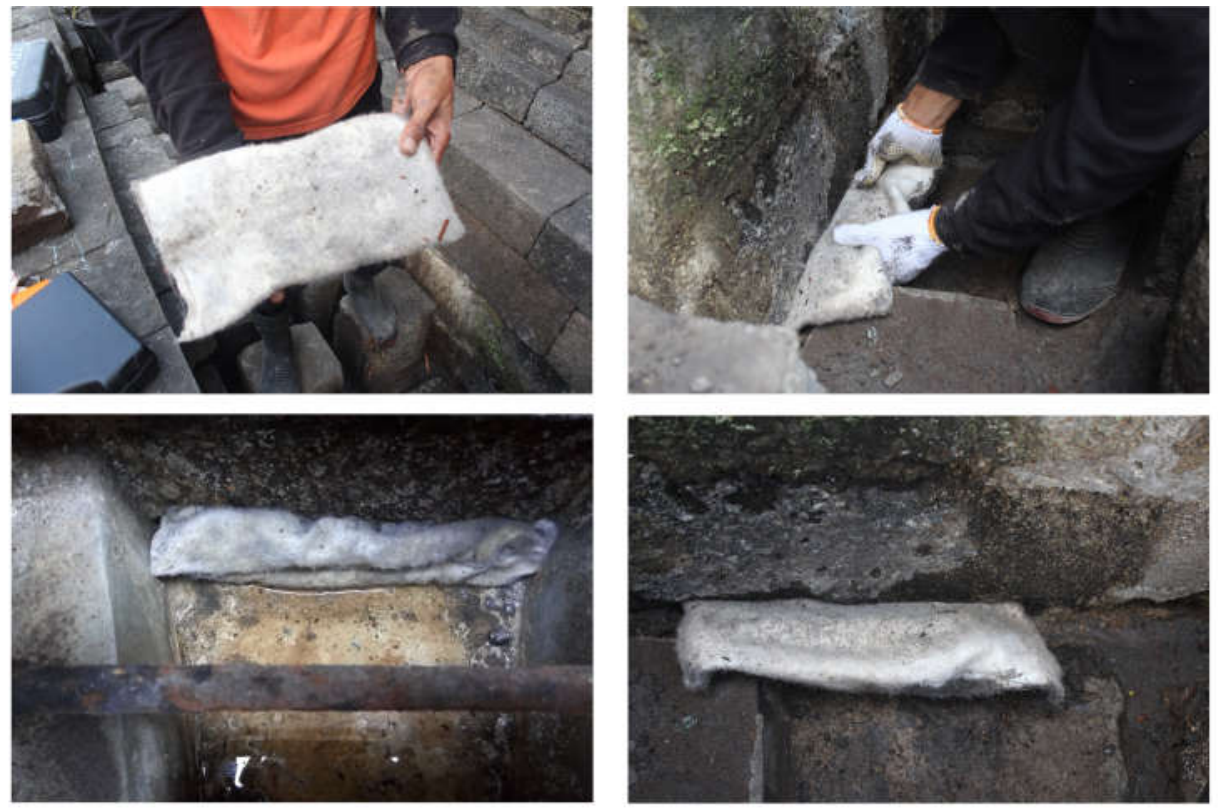

Gambar 18. Pemasangan kantong filter pada ujung luar saluran filter layer menutup ujung luar saluran filter layer dengan kantong filter.

Kantong filter terdiri dari kerikil dan kerakan yang dibungkus dengan geotekstil. Hal ini perlu dilakukan agar di masa mendatang saluran filter layer tidak mendapatkan limpasan material dari saluran drainase bawah lantai sehingga selalu dalam kondisi bersih. Selain itu air dari dalam bukit Candi Borobudur yang melewati saluran filter layer tetap dapat mengalir keluar dengan lancar menuju saluran drainase bawah lantai.

Setelah saluran filter layer dan saluran drainase bawah lantai bersih dari endapan material selanjutnya perlu dilakukan penanganan agar kedepannya material tanah/pasir dan sampah tidak masuk ke saluran drainase bawah lantai. Untuk itu perlu dipasang lapisan penyaring (geotekstil) di bawah lantai agar jika jika ada material pengotor yang masuk akan tertahan oleh lapisan ini tetapi air hujan tetap dapat masuk ke saluran drainase bawah lantai dengan lancar.

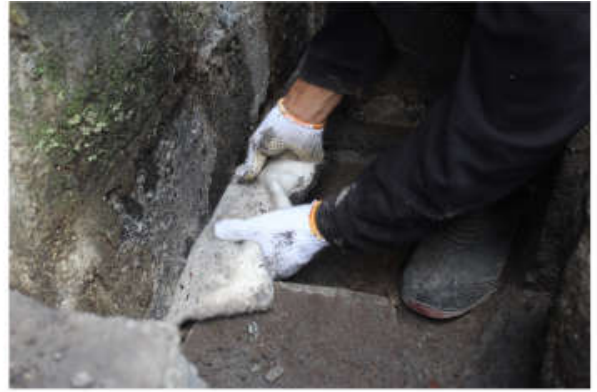

pada ujung luar saluran filter layer 


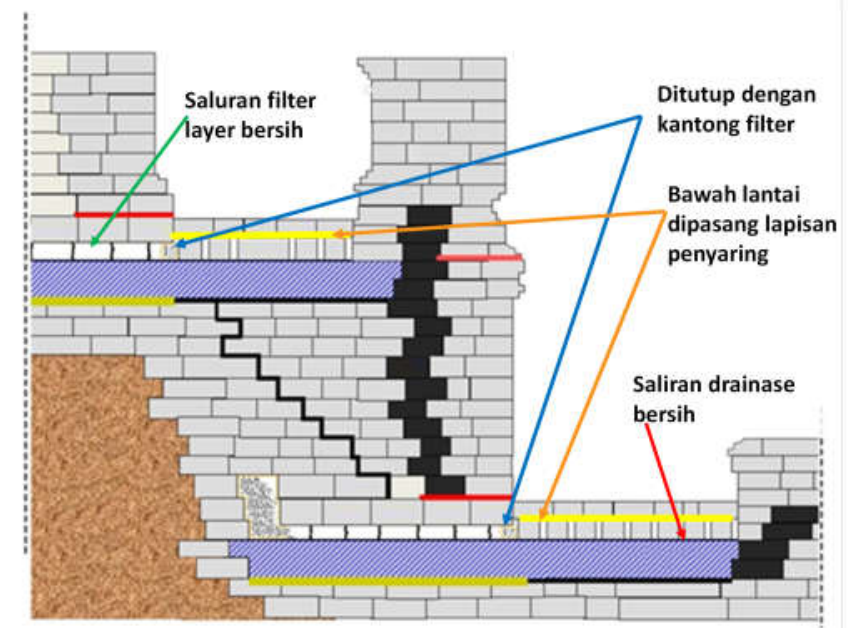

Gambar 19. Kondisi ideal saluran filter layer dan saluran drainase bawah lantai setelah dilakukan pembersihan

Dari percobaan yang telah dilakukan, waktu yang diperlukan untuk membersihkan $1 \mathrm{~m}^{2}$ saluran drainase bawah lantai sekitar 20 menit (1/4 jam). Sedangkan luas lantai yang memiliki saluran drainase bawah lantai adalah 4.019,53 $\mathrm{m}^{2}$ dengan rincian sebagai berikut :

- Lorong I : 831,11 $\mathrm{m}^{2}$

- Lorong II : 610,01 $\mathrm{m}^{2}$

- Lorong III : $530,88 \mathrm{~m}^{2}$

- Lorong IV : 499,68 $\mathrm{m}^{2}$

- Plateu : $1547,83 \mathrm{~m}^{2}$

\section{EVALUASI MONITORING GEOHIDROLOGI CANDI BOROBUDUR}

\section{Evaluasi Monitoring Filter Layer}

Monitoring filter layer pada awalnya dilakukan dengan mengukur debit dan kekeruhan air yang keluar dari bukit dan melewati filter layer. Monitoring ini telah dimulai sekitar tahun 2004 dan dilakukan pada 32 saluran filter layer yang memiliki bak penampung air. Tujuan pengukuran debit air adalah untuk melihat apakah filter layer masih bisa dilewati air dengan baik. Ketika debitnya kecil diinterpretasikan bahwa filter layer mengalami penyumbatan sehingga tidak dapat mengalirkan air dari dalam bukit dengan baik. Sedangkan pengukuran kekeruhan air adalah untuk melihat apakah filter layer masih dapat menyaring tanah bukit dengan baik. Ketika airnya keruh diinterpretasikan filter layer telah mengalami kerusakan dan ada tanah
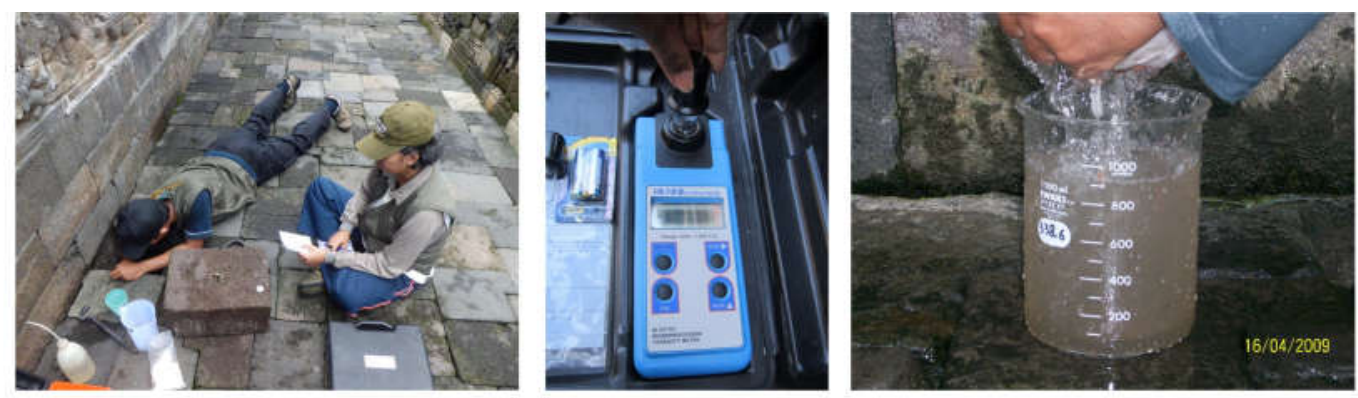

Gambar 20. Monitoring filter layer dengan pengukuran debit dan kekeruhan air 

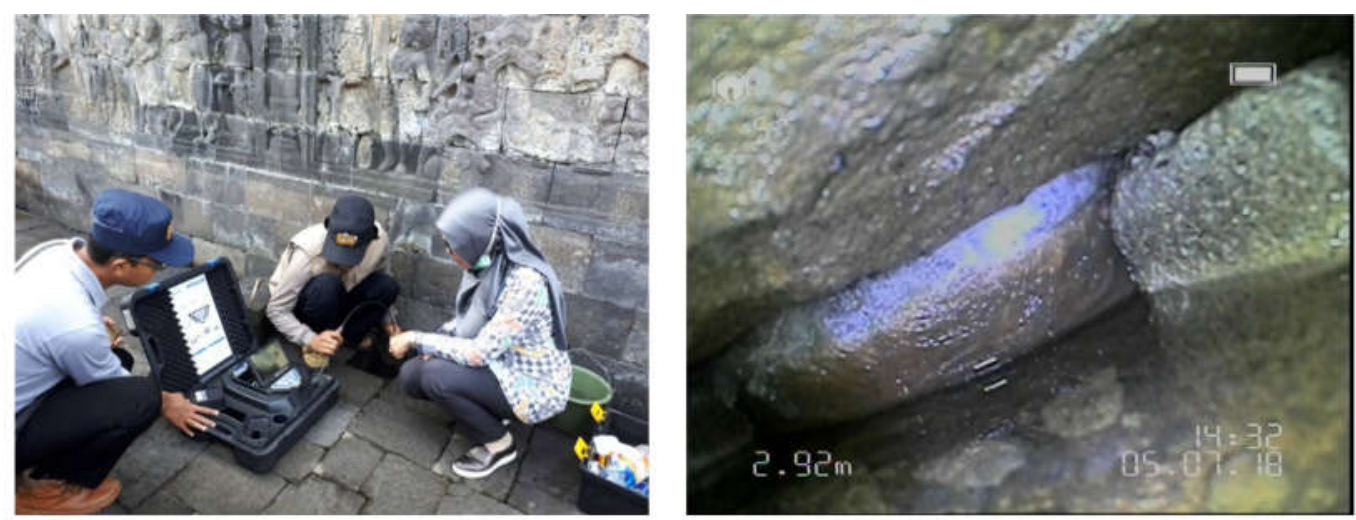

Gambar 21. Monitoring filter layer dengan alat videoscope untuk mengetahui gambaran visual filter layer

bukit yang terbawa keluar sehingga menyebabkan air mengalir menjadi keruh.

Dari pengamatan yang dilakukan ternyata saluran filter layer banyak terisi oleh material tanah/pasir sehingga debit dan kekeruhan air sangat dipengaruhi oleh banyaknya endapan material pada saluran tersebut. Ketika endapan materialnya banyak maka aliran air akan terhambat dan menjadi keruh sehingga seolah-olah debit airnya kecil dan kekeruhannya tinggi. Ini berarti metode monitoring dengan pengukuran debit dan kekeruhan air tidak dapat dipakai untuk mengetahui kondisi riil filter layer sehingga perlu diubah dengan metode yang baru. Untuk itu metode monitoring filter layer diubah dengan monitoring menggunakan videoscope untuk mengamati gambaran visual filter layer. Dengan metode ini kondisi riil filter layer dapat terlihat dengan jelas.

\section{Evaluasi Monitoring Muka Air Tanah Candi Borobudur Melalui Pipa Inklinometer}

Monitoring muka air tanah
Candi Borobudur melalui
pengukuran elevasi muka air pada
pipa inklinometer telah dimulai

sekitar tahun 2004. Pipa inklinometer adalah pipa yang ditanam pada Candi Borobudur dan digunakan untuk memasukkan alat inklinometer yaitu alat untuk memantau ada tidaknya pergeseran tanah bukit Candi Borobudur. Tim monitoring geohidrologi bersama ahli hidrologi dari UNESCO melakukan eksperimen untuk menentukan apakah ujung bawah pipa inklinometer dalam kondisi terbuka atau tertutup. Jika kondisinya terbuka berarti pipa inklinometer dapat digunakan untuk memantau muka air tanah Candi Borobudur. Sebaliknya jika kondisinya tertutup maka pipa inklinometer tidak dapat digunakan untuk pemantauan muka air tanah karena jika terdetensi ada air, maka air yang ada pada pipa tersebut bukan merupakan air tanah melainkan hanya air yang terjebak dalam pipa inklinometer.

Eksperimen dilakukan dengan mengisi air sampai pada elevasi tertentu pada semua pipa inklinometer. Selang sehari kemudian dilakukan pengecekan dengan pada pipa inklinometer untuk melihat apakah ada penurunan elevasi air. Jika elevasi air menurun berarti ujung bawah pipa inklinometer dalam 
Tabel 2. Ekeperimen penentuan penentuan kondisi ujung bawah pipa inklinometer

\begin{tabular}{lll}
\hline No & Lokasi & Hasil \\
\hline 1 & U1e & tertutup \\
\hline 2 & U2c & tertutup \\
\hline 3 & U3c & tertutup \\
\hline 4 & T2c & tertutup \\
\hline 5 & T3c & tertutup \\
\hline 6 & T3a & tertutup \\
\hline 7 & S1f & tertutup \\
\hline 8 & S2h & tertutup \\
\hline 9 & S3h & tertutup \\
\hline 10 & B2c & tertutup \\
\hline 11 & B2h & terbuka \\
\hline
\end{tabular}

kondisi terbuka sedangkan jika elevasi air tetap/stagnan maka ujung bawah pipa inklinometer dalam kondisi tertutup. Hasilnya adalah sebagian besar pipa inklinometer memiliki ujung bawah pipa yang tertutup (10 pipa tertutup dan hanya 1 pipa yang terbuka). Oleh karena itu hanya 1 pipa inklinometer yang dapat dijadikan sumur pantau yaitu pada lokasi B2h (sisi barat lantai 2 bidang h).

Namun demikian pada pipa inklinometer dengan ujung bawah terbuka (B2h) tidak pernah ditemukan adanya air sepanjang tahun baik pada musim kemarau maupun penghujan. Karena itu pengukuran muka air tanah melalui pipa inklinometer tidak lagi valid untuk dilakukan sehingga dihentikan pengambilan datanya.

Selain itu potensi kondisi air tanah bukit Candi Borobudur yang akan meluap dan menekan struktur Candi Borobudur kecil kemungkinannya. Hal ini dikarenakan beberapa hal yaitu :

a. Pemboran yang pernah dilakukan tidak pernah mencapai air tanah, diperkirakan 20-25 meter dibawah permukaan halaman candi. Tanah halaman candi dan tanah bukit dalam candi masih merupakan lapisan yang menerus (Sampurno, 1969).

b. Pada pipa inklinometer yang dapat dijadikan sebagai sumur pantau (B2h) tidak pernah ditemukan adanya air sepanjang tahun baik pada musim kemarau maupun penghujan, sehingga air tanah bukit Candi Borobudur meskipun dalam musim penghujan memiliki elevasi muka air tanah yang lebih dalam daripada panjang pipa (pipa inklinometer memiliki panjang 11-14 meter)

c. Ketika air di bukit Candi Borobudur dalam kondisi berlebih maka air tersebut akan keluar melalui filter layer yang dipasang mengelilingi lorong I-IV menuju saluran drainase bawah lantai.

\section{PENUTUP}

Saluran filter layer terdapat banyak endapan tanah/pasir yang 
menghambat aliran air keluarnya air dari dalam bukit Candi Borobudur. Akan tetapi endapan material pada saluran filter layer bukan berasal dari tanah bukit tetapi dari endapan pada saluran drainase bawah lantai yang terbawa masuk. Karena itu perlu dilakukan pembersihan saluran filter layer untuk memastikan semua saluran filter layer tidak tertutup oleh tanah/pasir sehingga dapat mengalirkan air dengan lancar. Selain itu beberapa filter layer diindikasikan telah mengalami kerusakan. Akan tetapi meskipun filter layer dalam kondisi rusak tetapi fungsinya sebagai lapisan penyaring masih bekerja baik.

Endapan tanah/pasir pada saluran drainase bawah lantai akan mengganggu kelancaran aliran air pada saluran ini yang karena posisi dasar saluran drainase menjadi lebih tinggi dan membuat dasar saluran menjadi rata/kemiringannya berkurang. Karena itu penting untuk memastikan saluran drainase bawah lantai dalam kondisi bersih dari endapan tanah/pasir agar air yang melewati saluran ini dapat mengalir dengan lancar serta tidak menghambat keluarnya air yang melewati saluran filter layer.

Kondisi saluran filter layer yang banyak terisi oleh material tanah/pasir menyebabkan debit dan kekeruhan air sangat dipengaruhi oleh banyaknya endapan material pada saluran tersebut. Karena itu perlu dilakukan perubahan metode monitoring filter layer dari yang sebelumnya dengan mengukur debit dan kekeruhan air yang keluar dari bukit dan melewati filter layer, menjadi monitoring menggunakan videoscope untuk mengamati gambaran visual filter layer.

Selain itu monitoring muka air tanah Candi Borobudur yang selama ini dilakukan melalui pipa inklinometer tidak perlu untuk dilanjutkan. Hal ini dikarenakan dari pengujian yang telah dilakukan, sebagian besar pipa inklinometer memiliki ujung bawah pipa tertutup sehingga data yang didapatkan menjadi tidak valid. 


\section{DAFTAR PUSTAKA}

Sampurno. (1969). Penelitian Tanah Dasar Tjandi Borobudur, Proyek Pelita Restorasi Borobudur, Magelang.

Soesilo, H., Parwoto, Sujono. (2002). Studi Masalah Air Tanah pada Candi Borobudur, Balai Studi dan Konservasi Borobudur, Magelang.

Soesilo, H., Puji S., Heri Y. (2004). Studi Kestabilan Lereng Bukit Candi Borobudur Terhadap Rembesan Air Tanah dan Karakteristik Serapan Air Hujan, Balai Konservasi Peninggalan Borobudur, Magelang.

Supriyadi, Andi. (2017). Pembuatan dan Karakterisasi Lentur Komposit Hybrid Serat Ijuk Acak/Serat Gelas Searah Bermatriks Epoksi, Universitas Muhammadiyah Yogyakarta

Todd, D. K.. (1980). Groundwater Hydrology, 2nd ed., John Wiley \& Sons, New York. 